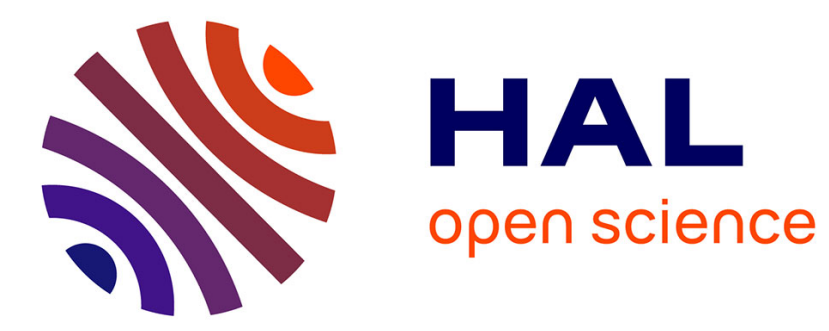

\title{
C3PO: Spontaneous and Ephemeral Social Networks (demo)
}

\author{
Nicolas Le Sommer, Pascale Launay, Yves Mahéo, Stéphane Frénot, \\ Frédérique Laforest, Damien Reimert, Amine Ghorbali
}

\section{- To cite this version:}

Nicolas Le Sommer, Pascale Launay, Yves Mahéo, Stéphane Frénot, Frédérique Laforest, et al.. C3PO: Spontaneous and Ephemeral Social Networks (demo). Tenth ACM MobiCom Workshop on Challenged Networks (ACM Chants@MOBICOM 2015), Sep 2015, Paris, France. 10.1145/2799371.2799372 . hal-01227519

\section{HAL Id: hal-01227519 \\ https://hal.science/hal-01227519}

Submitted on 11 Nov 2015

HAL is a multi-disciplinary open access archive for the deposit and dissemination of scientific research documents, whether they are published or not. The documents may come from teaching and research institutions in France or abroad, or from public or private research centers.
L'archive ouverte pluridisciplinaire HAL, est destinée au dépôt et à la diffusion de documents scientifiques de niveau recherche, publiés ou non, émanant des établissements d'enseignement et de recherche français ou étrangers, des laboratoires publics ou privés. 


\section{Demo: C3PO — Spontaneous and Ephemeral Social Networks}

\author{
Nicolas Le Sommer \\ IRISA, Université de Bretagne Sud
}

\author{
Pa
}

Stéphane Frénot

INRIA, Université de Lyon

\section{Damien Reimert INRIA}

\author{
Frédérique Laforest \\ Hubert Curien Lab., Université de \\ Saint Etienne \\ Amine Ghorbali \\ IRISA, Université de Bretagne Sud
}

\begin{abstract}
The C3PO project promotes the development of a new kind of spontaneous and ephemeral social networks dedicated to cultural, festive or sports events. They rely on opportunistic communication networks formed dynamically by mobile devices carried by event attendees. In this paper, we present both the opportunistic communication framework we have designed in project $\mathrm{C} 3 \mathrm{PO}$ and the Android mobile application we have developed using this framework. We also propose a demonstration, where we will invite conference attendees to use our Android mobile application to cover the CHANTS' 15 workshop by exchanging multimedia contents during this event.
\end{abstract}

\section{Categories and Subject Descriptors}

C.2.1 [Network Architecture and Design]: Store and forward networks

\section{Keywords}

Mobile Social Networking; Opportunistic Networking.

\section{INTRODUCTION}

Project C3PO proposes to investigate multimedia content exchange in a new type of social networks, so called Spontaneous and Ephemeral Social Networks (SESNs). Due to their spontaneous and ephemeral nature, SESNs are suited for happenings (e.g., conferences, cultural or sports events). They rely on a peer-to-peer distributed architecture spontaneously formed by mobile devices of event attendees. Opportunistic communication techniques are used to support the connectivity disruptions occuring in such dynamic networks. As a SESN is geographically constrained by the happening location, the set of users collaborating in the SESN is limited.

Permission to make digital or hard copies of part or all of this work for personal or classroom use is granted without fee provided that copies are not made or distributed for profit or commercial advantage and that copies bear this notice and the full citation on the first page. Copyrights for third-party components of this work must be honored. For all other uses, contact the Owner/Author. Copyright is held by the owner/author(s). Chants'15 September 11, 2015, Paris, France

ACM ISBN 978-1-4503-3543-0/15/09.

DOI: http://dx.doi.org/10.1145/2799371.2799372 .
A SESN can be created by any user and advertised to other users in the vicinity. When the happening stops, peers forming the SESN separate, devices are disconnected and the SESN vanishes. Multimedia contents are massively exchanged within the SESN: all peers receive all contents. Each peer can filter the contents it receives using a set of plugins. The C3PO project objectives are detailed in [2].

This paper is organized as follows. Section 2 provides an overview of the architecture of the C3PO Android mobile application. Sections 3 and 4 present respectively the opportunistic networking framework and toolkit and a plugin-based Web canvas for SESNs. We conclude by presenting our demonstration proposal.

\section{C3PO APPLICATION ARCHITECTURE}

C3PO targets mobile users carrying off-the-shelf mobile devices. The panel of devices being large and heterogeneous, genericity of the C3PO application is mandatory. C3PO aims at being independent from the operating system as much as possible, and therefore a large part of the C3PO application relies on the today's in-browser technologies.

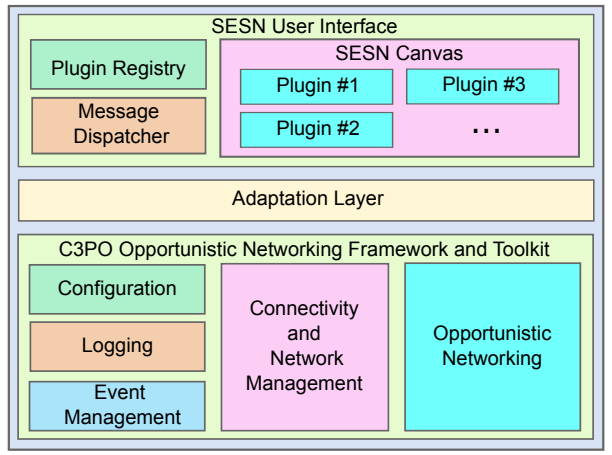

Figure 1: C3PO Application General Architecture

The C3PO application, whose the general architecture is represented in Figure 1, is structured in two parts: 1) a user interface implemented by a plugin-based Web canvas that manages interactions with the user and provides user-level functionalities as a set of configurable plugins, and 2) an opportunistic networking framework and a toolkit that make it possible to exploit the different 
short range wireless interfaces of mobile devices to interconnect them, and to perform an opportunistic data dissemination between devices.

\section{OPPORTUNISTIC NETWORKING FRAMEWORK AND TOOLKIT}

The C3PO opportunistic networking framework allows to develop Android-based mobile applications using a set of built-in functionalities provided in the $\mathrm{C} 3 \mathrm{PO}$ toolkit.

The Connectivity and Network Management module is responsible for the device discovery and the connection with neighboring devices. It supports different connectivity types, i.e. Bluetooth, Wi-Fi Legacy, Wi-Fi Direct and 3G/4G, that can be used jointly to form islands of interconnected devices.

The Opportunistic Networking module provides two communication paradigms, namely a topic-based publish/subscribe, and a channel-based send/receive. It defines a generic mechanism to forward messages in the network, tolerating connectivity disruptions between devices located in distinct islands. Different forwarding strategies can be devised, relying on epidemic and network flooding techniques, or implementing more sophisticated techniques relying on content-based, topic-based, community-based, contact frequency or social-based criteria.

Finally, the opportunistic networking framework defines three other modules of functionalities, that are respectively dedicated to the configuration of the framework, to the management of the events, and to $\log$ the traces that are generated by the framework (e.g., contact and message exchanges traces).

\section{A PLUGIN-BASED WEB CANVAS}

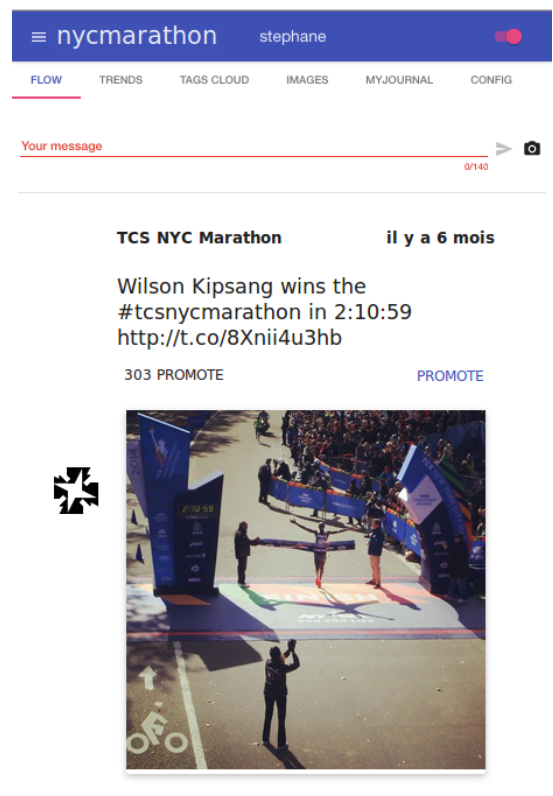

Figure 2: Event flow display

The SESN user interface is implemented by a plugin-based Web canvas. This canvas manages interactions with a member of a SESN. It is responsible for processing and presenting to the enduser data received by the networking framework. Using this canvas the end-user can create new contents to be exchanged with other end-users; he can also promote a received content to stress his special interest.

Depending on the SESN happening type, messages may carry very different contents and thus message processing requires extensibility. Plugins are responsible for the processing of incoming messages and for the interaction with the end-user [1]. Each plugin has a specific message processing unit, dedicated to a kind of messages. For each incoming message, the Message Dispatcher selects in the Plugin Registry the corresponding plugins and calls their processing unit. A SESN Canvas organizes plugins in the graphical user interface. Devices in the same SESN have a set of identical plugins, but some more powerful devices may also have additional specific ones.

Some plugins have already been developed in the C3PO project, such as a) the "Flow" plugin (see the screenshot on Figure 2) that takes all the received and emitted messages and displays them as a list ordered with the last received first; b) the "Tags Cloud" plugin that takes all the incoming messages and builds a tags cloud that reflects the frequency of each hashtag in the message set; and c) the "My Journal" plugin that displays all trending messages interleaved with the messages manipulated by the user. At the SESN termination, it provides a summary of the happening.

\section{DEMONSTRATION PROPOSAL}

Our demonstration will aim to show to the conference attendees how to create a SESN dedicated to the CHANTS'15 workshop using the C3PO Android application, how to publish messages and photos, and how to promote some contents in the SESN. Conference attendees will also be invited to install the C3PO Android application on their own smartphones or tablets in order to participate in this SESN. Doing so, they will be able to comment the presentations, to share photos during the conference and the social events, to vote for the best presentation or demonstration.

We expect to obtain an interesting feedback from volunteer users during the conference in order to improve our C3PO application. Moreover, trace files generated by the C3PO application on each mobile device will be collected at the end of the workshop. The confidentiality of the user communication is here guaranteed: the trace files contain only details about the connections between devices and about the ID of the messages they exchange, but no information is recorded about the actual content of the messages exchanged between these devices. These traces could be reused for simulation purposes. They also should help understand how an opportunistic network relying on different wireless technologies (i.e., Bluetooth, Wi-Fi Direct) is formed in real conditions, and should help us to improve our opportunistic communication framework in the future.

\section{Acknowledgments}

This work is done in the C3PO project, supported by the French ANR (Agence Nationale de la Recherche) under contract ANR-13-CORD-0005. http://www.c3po-anr.fr/

\section{REFERENCES}

[1] S. Frénot and S. Grumbach. An in-browser microblog ranking engine. In Advances in Conceptual Modeling - ER ECDM-NoCoDA workshop, Florence, Italy, October 2012, volume 7518 of $L N C S$, pages 78-88.

[2] F. Laforest, N. Le Sommer, and S. Frénot et al. C3PO: a Spontaneous and Ephemeral Social Networking Framework for a collaborative Creation and Publishing of Multimedia Contents. In MoWNet 2014, pages 1-6, Rome, Italy, 2014. Elsevier. 